\title{
Comparison between Two Different Cervical Interbody Fusion Cages in One Level Stand-alone ACDF : Carbon Fiber Composite Frame Cage Versus Polyetheretherketone Cage
}

\author{
Minwook Yoo', Wook-Ha Kim², Seung-Jae Hyun ${ }^{1}$, Ki-Jeong Kim, \\ Tae-Ahn Jahng ${ }^{1}$, Hyun-Jib Kim ${ }^{1}$ \\ ${ }^{I}$ Department of Neurosurgery, Spine Center, Seoul National University Bundang Hospital, \\ Seoul National University College of Medicine, Seongnam, \\ ${ }^{2}$ Department of Neurosurgery, MH Woori Hospital, Changwon, Korea
}

\begin{abstract}
Objective: The authors conducted a retrospective study to compare the implantation of carbon fiber composite frame cages (CFCFCs) to the implantation of polyetheretherketone (PEEK) cages after anterior cervical discectomy for cervical degenerative disc disease. In addition, the predictive factors that influenced fusion or subsidence were investigated.

Methods: A total of 58 patients with single-level degenerative disc disease were treated with anterior cervical discectomy and implantation of stand-alone cages; CFCFCs were used in 35 patients, and PEEK cages were used in 23 patients. Preoperative and postoperative radiological and clinical assessments were performed.

Results: During the mean follow-up period of 41 months, fusion occurred in 43 patients (74.1\%), and subsidence developed in 18 patients (31.0\%). Pain decreased in all patients, and the patients' satisfaction rate was $75.9 \%$. Neither fusion nor subsidence was related to the clinical outcome. There were no significant differences in the clinical and radiological outcomes between the CFCFC and the PEEK cage groups. Smoking history $(\mathrm{p}=0.023)$ was significantly associated with pseudarthrosis, and cage height $(\geq 7 \mathrm{~mm})(\mathrm{p}=0.037)$ were significantly associated with subsidence.

Conclusion: The clinical and radiological results were similar between the CFCFC and the PEEK cage groups. Fusion or subsidence did not affect the clinical outcomes. Smoking history and cage height $(\geq 7 \mathrm{~mm})$ were predictive factors for pseudarthrosis or subsidence in anterior cervical discectomy and fusion with stand-alone cages.
\end{abstract}

Key Words: ACDF $\cdot$ Carbon cage $\cdot$ Polyetheretherketone cage

\section{INTRODUCTION}

Anterior cervical discectomy and fusion (ACDF) is an effective treatment for cervical disc disease. Although autologous iliac bone graft material has been considered to be a superior fusion material for cervical arthrodesis ${ }^{13,14}$, donor site morbidity is problematic ${ }^{24)}$. To overcome this problem, various materials have been used as substitutes for autografts in $\mathrm{ACDF}^{5,30)}$.

- Received: May 12, 2014 - Revised: July 18, 2014

- Accepted: August 1, 2014

Corresponding Author: Ki-Jeong Kim, MD, PhD

Department of Neurosurgery, Spine Center Seoul National University Bundang Hospital, 166 Gumi-ro, Bundang-gu, Seongnam, 463-707, Korea

Tel: +82-31-787-7166, Fax: +82-31-787-4097

E-mail: kijeong@snu.ac.kr

®This is an Open Access article distributed under the terms of the Creative

Commons Attribution Non-Commercial License (http://creativecommons.org/ licenses/by-nc/3.0/) which permits unrestricted non-commercial use, distribution, and reproduction in any medium, provided the original work is properly cited.
Among these materials, cervical interbody cages are widely used.

Cages were introduced because of their theoretical ability to restore and preserve disc height and lordosis as well as prevent graft collapse ${ }^{14)}$. Cages that are filled with cancellous bone reduce donor site pain, which is a common problem that is associated with the harvesting of structural iliac grafts ${ }^{29}$. There are several types of cages that have been developed for ACDF, including titanium, carbon fiber, and polyethere- therketone (PEEK) cages.

Although cages have been frequently used for ACDF, to our knowledge, only a few reports on the clinical and radiological outcomes between the different types of cages implanted in ACDF have been published ${ }^{16,19)}$. Therefore, we retrospectively collected the medical records of patients who under- went one-level ACDF with implantation of stand-alone carbon fiber composite frame cages (CFCFCs) or PEEK cages. The purpose of the present study was to compare the clinical and radiological outcomes of the implantation of CFCFCs to those of the implantation of PEEK cages and to investigate the predi- 
ctive factors for pseudarthrosis and subsidence.

\section{MATERIALS AND METHODS}

\section{Patient Population}

Between July 2004 and June 2009, one-level ACDF procedures with implantation of stand-alone cages were performed in 165 consecutive patients. Of those 165 patients, 58 (35.2\%) were included in the present study according to the following inclusion criteria: (1) one-level cervical degenerative disc disease was demonstrated on plain radiography and magnetic resonance imaging (MRI); (2) radiculopathy and/or myelopathy that was consistent with the radiological findings was exhibited; (3) unsuccessful conservative therapy was administered for at least 6 weeks; (4) a stand-alone CFCFC or PEEK cage was implanted. CFCFCs were used in 35 patients, and PEEK cages were used in 23 patients; (5) clinical and radiological follow up was continued for at least 12 months; and (6) there was no previous history of cervical spine surgery. Institutional review board approval was obtained before the collection or analysis of any data associated with the present study.

The mean age of the patient population was 52.6 years (range, $33-70)$, and $32(55.2 \%)$ of the patients were male. Twentytwo patients (37.9\%) smoked during the perioperative ACDF period. Of the 58 enrolled patients, 36 (62.1\%) underwent $\mathrm{ACDF}$ at the C5-C6 level, which was the most common location. Cages with a 7-mm height were the most frequently implanted and were used in $40(69.0 \%)$ of the 58 patients. Autologous iliac bone was harvested in 23 patients (39.7\%), and allograft bone was used in 35 patients (60.3\%). The patient characteristics between the two cage groups are shown in Table 1. The mean clinical follow-up period was 41 months (range, 15-75), and the mean radiological follow- up period was 24 months (range, 12-60).

\section{Surgical Methods}

The operations were performed by the two senior authors. The cervical spine was exposed using a standard anterolateral approach. The operated level was confirmed with fluoroscopic imaging, and the intervertebral disc space was opened using a Caspar distractor. Complete discectomy, removal of the posterior longitudinal ligament and osteophyte, and careful end plate preparation were performed. After the dura was decompressed, the appropriate cage size was determined using both preoperative templating and intraoperative evaluations with a trial cage to confirm the initial stability. The cages were filled with allograft or autograft material, which was harvested from the anterior iliac crest using a standard approach, and gently impacted into the prepared disc space. Before closure of the superficial layers, a control intraopera- tive lateral radiographic image was obtained, and the correct positioning of the implant was confirmed. Postoperatively, all patients were instructed to use a soft cervical collar for 3 months.

\section{Implant Description}

There were two different cage systems used in the present study: the CFCFC (Co-Ligne AG, Zurich, Switzerland) and the PEEK cage (Solis ${ }^{\circledR}$, Stryker Spine, Cestas, France). Both cages are highly radiolucent and have markers to aid in their visualization, radiological assessment, and identification of their position on plain X-ray films. The CFCFC is composed of a medical-grade composite of long fiber carbon that is encapsulated in a polyetherketon-etherketon-keton matrix; the CFCFCs measure 12 or $13.5 \mathrm{~mm}$ in width, are $12 \mathrm{~mm}$ deep, and are available in 6-, 7-, 8-, or 9-mm anterior heights with $5^{\circ}$ of lordosis. These cages have two hollow centers and are wedge-

Table 1. Patients baseline characteristics

\begin{tabular}{|c|c|c|c|}
\hline Factors & $\begin{array}{l}\text { CFCFC } \\
\text { group }\end{array}$ & $\begin{array}{c}\text { PEEK } \\
\text { cage group }\end{array}$ & p-value \\
\hline No. of patients & 35 & 23 & \\
\hline Mean age (years) & 51.8 & 53.9 & $0.436^{a}$ \\
\hline Male & 22 & 10 & $0.119^{b}$ \\
\hline Smoking history & 14 & 8 & $0.453^{b}$ \\
\hline \multicolumn{4}{|l|}{ Symptoms } \\
\hline Radiculopathy & 15 & 10 & $0.963^{b}$ \\
\hline Myelopathy & 6 & 8 & $0.125^{b}$ \\
\hline Myeloradiculopathy & 9 & 2 & $0.099^{\circ}$ \\
\hline \multicolumn{4}{|l|}{ Level } \\
\hline C3-C4 & 3 & 1 & $0.478^{\circ}$ \\
\hline C4-C5 & 2 & 4 & $0.162^{\circ}$ \\
\hline C5-C6 & 20 & 16 & $0.340^{b}$ \\
\hline C6-C7 & 10 & 2 & $0.064^{c}$ \\
\hline Cage height $\geq 7 \mathrm{~mm}$ & 33 & 7 & $<0.005^{c}$ \\
\hline Autograft & 13 & 10 & $0.416^{b}$ \\
\hline \multicolumn{4}{|l|}{ Mean $\mathrm{TIH}$} \\
\hline Anterior & 35.88 & 34.63 & $0.150^{\circ}$ \\
\hline Middle & 33.65 & 32.84 & $0.327^{a}$ \\
\hline Posterior & 35.26 & 34.48 & $0.366^{\mathrm{a}}$ \\
\hline Mean angle of the FSU & -3.77 & -1.96 & $0.210^{a}$ \\
\hline $\begin{array}{l}\text { Mean Cobb angle from } \\
\text { the } C 2 \text { to } C 7 \text { vertebrae }\end{array}$ & -15.69 & -12.05 & $0.236^{a}$ \\
\hline
\end{tabular}

CFCFC, carbon fiber composite frame cage; PEEK, polyetheretherketone; $\mathrm{TIH}$, total intervertebral height; FSU, functional segmental unit.

${ }^{\mathrm{a}}$ The student t-test

bThe $\chi^{2}$ test

'The Fisher's exact test 
shaped so that the anterior height of the cages is larger than the posterior height (Fig. 1). The PEEK cages are ring shaped with 1-mm titanium spikes and retentive teeth on the top and bottom, which improve the fixation of the cage to the bone (Fig. 2). These cages have a hollow center and a convex surface and are available with an internal anteroposterior diameter of 12 or $14 \mathrm{~mm}$ and a height of 5,6 , or $7 \mathrm{~mm}$ with $4^{\circ}$ of lordosis.

\section{Assessment of Fusion and Subsidence}

Preoperative radiological examinations, such as plain radiographs and MRI, were performed in all patients. Immediate postoperative radiographs were obtained one day after surgery, and subsequent radiological follow-up was performed at $1,3,6$, and 12 months postoperatively. After 12 months, follow-up radiographs were ordered more than once per year depending on the fusion or subsidence status of each patient. Radiological images included anteroposterior, lateral, and flexion-extension lateral radiographs.

Fusion was defined as a distance change of less than $2 \mathrm{~mm}$ between the tips of the spinous processes of the surgically treated level based on flexion-extension lateral radiographs (Fig. 3) $)^{4}$. Subsidence was defined as a decrease in the total intervertebral height $(\mathrm{TIH})$ between the two fused vertebral bodies and was determined by comparing the postoperative follow-up lateral cervical radiographs to the one-day post-

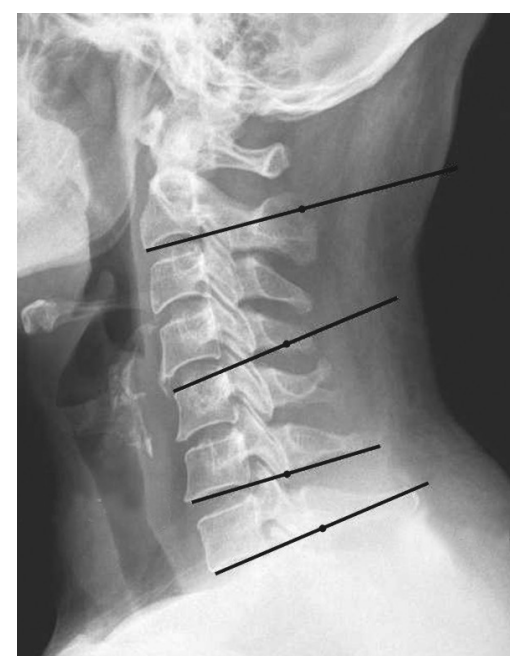

Fig. 1. Preoperative standard lateral radiograph in a patient who underwent a C5-C6 anterior cervical discectomy and fusion. The Cobb angle between the C2 and C7 vertebrae is determined by measuring the angle formed by the lines between the lower endplates of the $\mathrm{C} 2$ and $\mathrm{C} 7$ vertebrae. The angle of the functional segmental unit (C5-C6) is determined by measuring angle between the lines of the upper endplate of the C5 vertebra and the lower endplate of the C6 vertebra. operative radiogra- $\mathrm{phs}^{28)}$. The TIH of two fused vertebral bodies was measured as the distance between the anterior, middle, and posterior points of the upper end plate of the cranial vertebral body and the lower end plate of the caudal vertebral body (Fig. 4). A decrease in the TIH of greater than $3 \mathrm{~mm}$ based on any of the three height measurements was considered to be significant subsidence ${ }^{10}$.

The height of the intervertebral disc of the surgically treated level was assessed as the height at the mid-portion on the preoperative mid-sagittal MRI image. The angle of the functional segmental unit (FSU) was defined as the angle between the upper end plate of the upper vertebral body and the lower

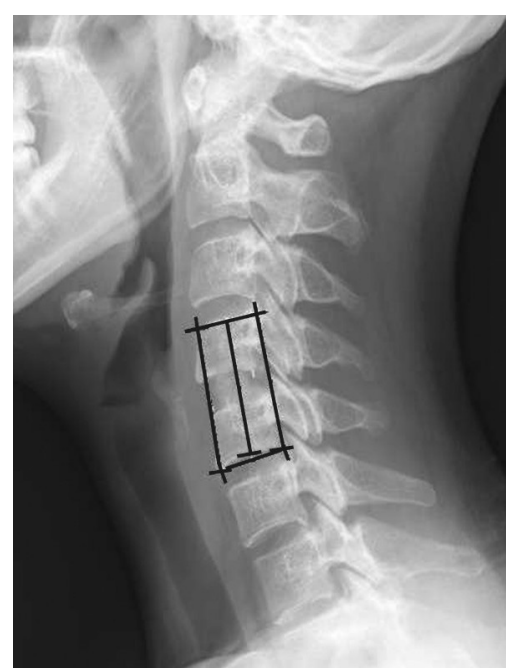

Fig. 2. Radiographic image showing the total intervertebral height of the two fused vertebral bodies. The distances between the anterior, middle, and posterior margins of the upper end plate of the more cranial vertebral body and those of the lower end plate of the more caudal vertebral body were measured.
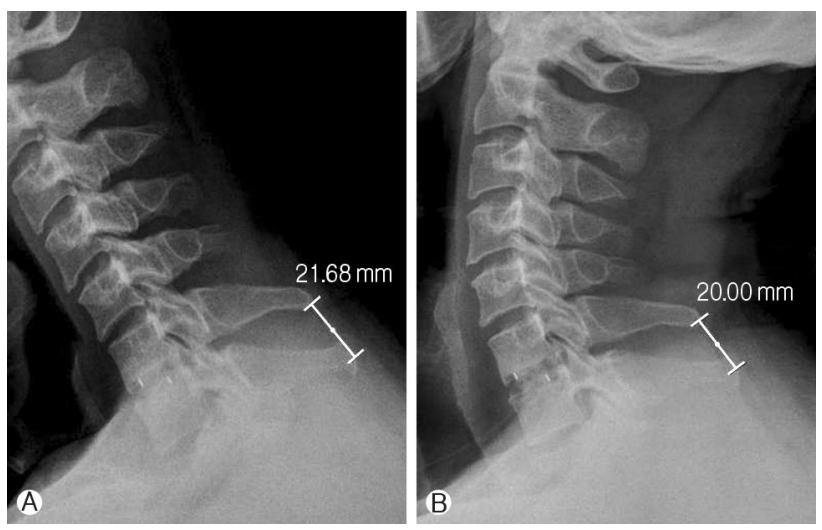

Fig. 3. Flexion-extension lateral radiographs. The distance between the tips of the spinous processes of the two fused vertebral bodies was measured. A change in the distance of less than $2 \mathrm{~mm}$ was defined as fusion. 
end plate of the lower vertebral body, based on the lateral radiographs (Fig. 5). The Cobb angle between the $\mathrm{C} 2$ and $\mathrm{C} 7$ vertebrae was estimated. Negative values for the angle of the FSU and the Cobb angle indicated lordotic angles. The curvature of the cervical spine in the neutral position was described as lordotic, straight, or kyphotic ${ }^{2}$. If the posterior wall of the vertebral bodies of the $\mathrm{C} 3$ to $\mathrm{C} 6$ vertebrae were located anterior to the line between the posterior inferior borders of the $\mathrm{C} 2$ and $\mathrm{C} 7$ vertebrae, the curvature of the cervical spine was described as lordotic; if the wall was located at this line, the curvature was described as straight, and if the wall was located posterior to this line, the curvature was described as kyphotic.

Radiological measurements were performed on digital radiographs using built-in software (INFINITT PACS, INFINITT Healthcare, Korea). Two independent observers, who were blinded to the patients' clinical data, assessed each case for the status of the fusion and subsidence and performed measurements of the radiographic parameters in duplicate. The mean values of the radiographic parameters collected by the two observers were used for the analysis to correct for the intra- and inter-observer reliability.

\section{Clinical Outcomes}

Clinical outcomes were assessed preoperatively and at the last follow-up visit. The visual analog scale (VAS) (score range, $0-10 ; 0$ indicates no pain and 10 indicates the worst pain imaginable) was used to assess neck and arm pain. The neck disability index (NDI) was used to measure the functional impact of the patients' neck discomfort. The 10 sections of the

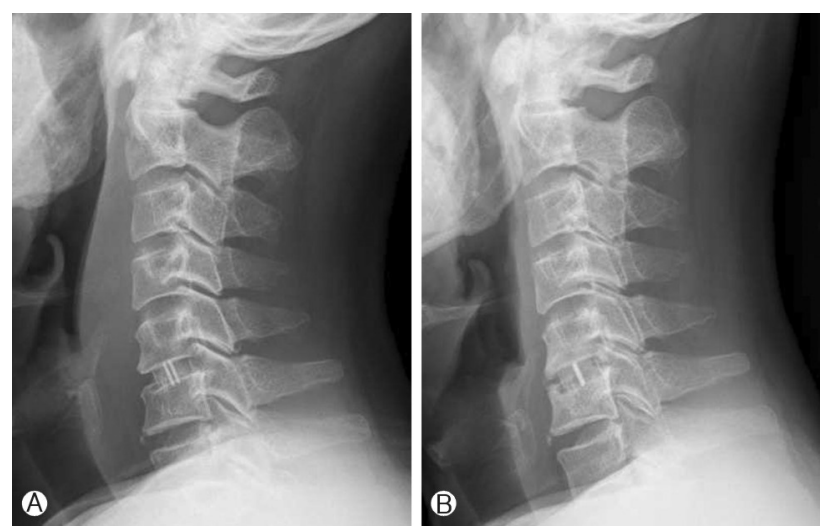

Fig. 4. Standard lateral radiograph obtained one day and 6 months after a C5-C6 anterior discectomy and fusion with a standalone polyetheretherketone (PEEK) cage in a 63-year-old man. After 6 months, complete fusion at the operated level was observed despite the cage sinking to the lower end plate of the C5 vertebra and the upper end plate of the C6 vertebra.
NDI (pain intensity, personal care, lifting, reading, headaches, concentration, work, driving, sleeping, and recreation) were scored from 0 to 5 and were summed for a total score between 0 (no pain or difficulties) and 50 (highest score for pain and difficulty with all activities). Overall clinical outcome was assessed by the patient as excellent, good, fair, or poor according to Odom's criteria ${ }^{20)}$. If the outcome was excellent or good, the patient was considered to be satisfied with the surgery.

\section{Statistical Methods}

Descriptive data are presented as mean \pm standard deviation. For the comparison of nonparametric data, the Mann-Whitney $\mathrm{U}$ test, the $\chi^{2}$ test, or the Fisher's exact test was used. For the parametric unrelated data, an unpaired t-test was used. A paired t-test was used for the comparison between the preand postoperative continuous variables. Logistic regression analysis for the correlated data using generalized estimating equations was performed to study the correlation between the possible predictive variables and the occurrence of fusion and subsidence. The inter- and intra-class correlation coefficient (ICC) test was performed to determine the inter- and intra-observer reliability of the two sets of measurements obtained by the two observers. ICC was considered to be in the excellent range based on the descriptions by Shrout and Fleiss (poor, <0.4; fair to good, 0.4-0.7; and excellent, $>0.7$ ) 2 . A value of $\mathrm{p}<0.05$ was considered to be statistically significant. All analyses were performed using SPSS 17.0 for Windows (SPSS, Inc., Chicago, IL).

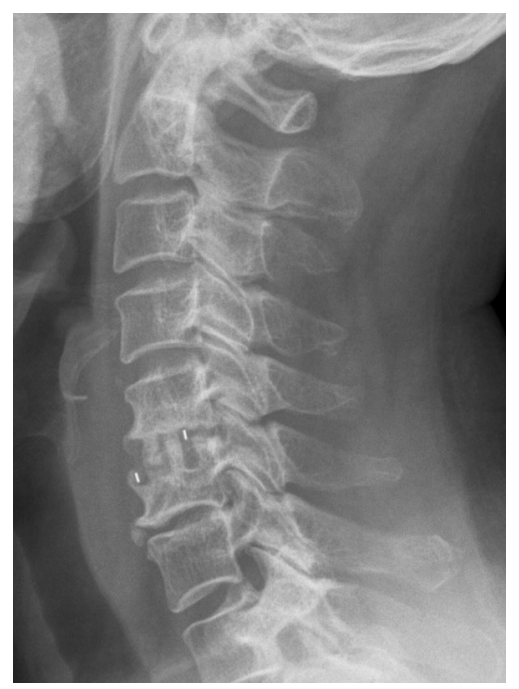

Fig. 5. Standard lateral radiograph obtained 6 months after a C5-C6 anterior cenvical discectomy and fusion with a stand-alone carbon fiber composite frame cage in a 64-year-old woman. After 6 months, subsidence was observed at the operated level. 


\section{RESULTS}

\section{Radiological Results}

Fusion at the operated level was observed in 27 (46.6\%), $40(69.0 \%)$, and $43(74.1 \%)$ of the 58 patients at the 6-month, 12-month, and ultimate follow-up visits, respectively. Subsidence was observed in 18 patients (31.0\%) and occurred within 6 months postoperatively in $14(77.8 \%)$ of those 18 patients.

The mean preoperative anterior, middle, and posterior TIHs were $35.38 \pm 3.22 \mathrm{~mm}, 33.33 \pm 3.06 \mathrm{~mm}$, and $34.95 \pm 3.16 \mathrm{~mm}$, respectively. Postoperatively, there was a significant increase in the TIHs. However, the TIHs returned to the preoperative values on the 6-month follow-up radiographs, which persisted throughout the rest of the follow-up period.

The mean preoperative angle of the FSU was $-3.06 \pm 5.34^{\circ}$ and became more lordotic postoperatively at $-6.94 \pm 4.87^{\circ}$. However, this decrease in the angle of the FSU gradually reversed to produce a mean value of $-4.02 \pm 4.49^{\circ}$ at the 6 -month follow-up, which was similar to the preoperative value $(p=0.105)$. The mean Cobb angle between the C2 and C7 vertebrae did not change significantly $(p=0.221)$. The details of the radiological results are shown in Table 2 .
There were no significant differences in the preoperative and postoperative TIHs, angles of the FSU, and Cobb's angles between the C2 and C7 vertebrae between the two cage groups. These radiological parameters showed high reliability (Table 3).

\section{Clinical Results}

Overall neck and arm pain decreased significantly from a mean preoperative VAS score of $4.1 \pm 3.5$ and $6.8 \pm 2.7$, respectively, to $2.5 \pm 2.5(\mathrm{p}=0.001)$ and $2.4 \pm 2.4(\mathrm{p}<0.001)$ at the ultimate follow-up visit, respectively. Neck discomfort also decreased significantly from a mean preoperative NDI score of $11.5 \pm 9.5$ to an NDI score of $6.4 \pm 6.2$ at the ultimate follow-up visit $(\mathrm{p}<0.001)$. Overall, 16 patients $(27.6 \%)$ had an excellent outcome, 28 (48.3\%) patients had a good outcome, $13(22.4 \%)$ patients had a fair outcome, and one (1.7\%) patient had a poor outcome (Table 4). These clinical outcomes were not correlated with radiological results, such as pseudarthrosis or subsidence (Table 5). In addition, there were no differences in the clinical outcomes between the two cage groups.

\section{Factors that Influenced Fusion and Subsidence}

To clarify the predictive factors for fusion or subsidence,

Table 2. The radiological results

\begin{tabular}{|c|c|c|c|c|c|}
\hline & \multicolumn{3}{|c|}{ Total intervertebral height (mm) } & \multirow{2}{*}{$\begin{array}{l}\text { The angle of } \\
\text { the FSU }\left(^{\circ}\right)\end{array}$} & \multirow{2}{*}{$\begin{array}{c}\text { The Cobb angle between the } \\
\left.\text { C2 and C7 vertebrae ( }{ }^{\circ}\right)\end{array}$} \\
\hline & Anterior & Middle & Posterior & & \\
\hline Preoperative Postoperative & $35.38 \pm 3.22$ & $33.32 \pm 3.06$ & $34.95 \pm 3.16$ & $-3.06 \pm 5.33$ & $-14.22 \pm 11.29$ \\
\hline At 1 month $^{b}$ & $36.50 \pm 3.28$ & $34.17 \pm 2.96$ & $35.42 \pm 3.07$ & $-5.05 \pm 4.84$ & $-12.89 \pm 8.41$ \\
\hline At 6 month $^{c}$ & $35.74 \pm 3.12$ & $33.56 \pm 2.87$ & $34.98 \pm 2.87$ & $-4.02 \pm 4.49$ & $-15.69 \pm 9.04$ \\
\hline At the ultimate follow-up & $35.38 \pm 3.14$ & $33.40 \pm 2.99$ & $34.94 \pm 3.08$ & $-3.39 \pm 5.17$ & $-14.68 \pm 9.29$ \\
\hline
\end{tabular}

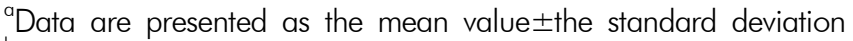

bThe radiological results at 1 month postoperatively except the Cobb angle between the C2 and C7 vertebrae show significant change compared with those of the preoperative state $(p<0.01$ for all four parameters, paired t-test)

'The radiological parameters at 6-month postoperatively show a significant change compared with those of postoperative 1 month $(p<0.01$, paired t-test), and no difference compared with those of preoperative state $(p>0.05$, paired t-test $)$

Table 3. The intra- and interobserver reliability using intra- and interclass correlation coefficient

\begin{tabular}{lccccc}
\hline \hline \multirow{2}{*}{ Test } & \multicolumn{3}{c}{ Total intervertebral height } & \multirow{2}{*}{ The angle of the FSU } & $\begin{array}{c}\text { The Cobb angle between the } \\
\text { C2 and C7 vertebrae }\end{array}$ \\
\cline { 2 - 4 } & Anterior & Middle & Posterior & & \\
Intraobserver & & & & & 0.891 \\
Observer 1 & 0.998 & 0.995 & 0.997 & 0.988 & 0.994 \\
$\begin{array}{l}\text { Observer 2 } \\
\text { Interobserver }\end{array}$ & 0.947 & 0.998 & 0.992 & 0.957 & \\
$\quad 1^{\text {st }}$ measurement & 0.976 & 0.966 & 0.983 & 0.946 & 0.994 \\
$2^{\text {nd }}$ measurement & 0.973 & 0.996 & 0.987 & 0.959 & 0.879 \\
\hline
\end{tabular}

FSU, functional segmental unit 
Table 4. Clinical and radiologic outcomes between CFCFC and PEEK cage groups

\begin{tabular}{lccc}
\hline \hline \multicolumn{1}{c}{ Factors } & CFCFC group & $\begin{array}{c}\text { PEEK cage } \\
\text { group }\end{array}$ & p-value \\
\hline Neck VAS, mean & & & \\
$\quad$ Preoperative & 4.06 & 4.26 & $0.832^{a}$ \\
$\quad$ Last F/U & 2.54 & 2.39 & $0.822^{a}$ \\
Arm VAS, mean & & & \\
$\quad$ Preoperative & 7.11 & 6.35 & $0.292^{a}$ \\
$\quad$ Last F/U & 2.49 & 2.17 & $0.628^{a}$ \\
NDI, mean & & & \\
$\quad$ Preoperative & 10.17 & 13.43 & $0.203^{a}$ \\
$\quad$ Last F/U & 6.14 & 6.83 & $0.685^{a}$ \\
Successful outcome & 26 & 18 & $0.492^{b}$ \\
Fusion & $24(68.6 \%)$ & $19(82.6 \%)$ & $0.232^{a}$ \\
Subsidence & $12(34.3 \%)$ & $6(26.1 \%)$ & $0.509^{a}$ \\
\hline
\end{tabular}

CFCFC, carbon fiber composite frame cage; PEEK, polyetheretherketone; VAS, visual analog scale; NDI, neck disability index; F/U, follow-up

${ }^{a}$ The student t-test

'The $\chi^{2}$ test

'Successful outcome indicates an excellent or good outcome based on Odom's criteria ${ }^{22)}$

Table 5. Statistical analysis of two correlative factors (pseudarthrosis and subsidence) that affect clinical outcomes after one-level anterior cervical discectomy with stand-alone cages

\begin{tabular}{lcccccc}
\hline \hline & \multicolumn{2}{c}{ Pseudarthrosis } & & \multicolumn{2}{c}{ Subsidence } \\
\cline { 2 - 3 } \cline { 5 - 6 } Clinical outcomes & Odds ratio & p-value & & Odds ratio & -value \\
\hline Neck VAS & 1.529 & $0.052^{a}$ & & 1.168 & $0.356^{a}$ \\
Arm VAS & 0.864 & $0.217^{a}$ & & 0.935 & $0.520^{a}$ \\
NDI & 0.830 & $0.057^{a}$ & & 0.924 & $0.273^{a}$ \\
\hline
\end{tabular}

${ }^{\mathrm{a}}$ The $\chi^{2}$ test

the following patient characteristics and clinical features were evaluated: age ( $>60$ years), gender, smoking history, implanted level (C5-C6 vs. others), cage style, cage height $\geq 7 \mathrm{~mm}$, autograft vs. allograft, preoperative disc height, preoperative FSU angle (lordosis), and preoperative cervical curvature (lordosis).

In univariate analysis, smoking history was correlated with fusion. The statistical results are shown in Table 6. In multivariate analysis, smoking history was an independent predictive factor for pseudarthrosis (OR=0.173; 95\% CI, 0.038-0.788; $\mathrm{p}=0.023$ ). Subsidence, in univariate analysis, was influenced by cage height $\geq 7 \mathrm{~mm}$ and preoperative disc height. In multivariate analysis, only cage height $\geq 7 \mathrm{~mm}(\mathrm{OR}=15.808 ; 95 \%$ CI, 1.183-211.156; $\mathrm{p}=0.037$ ) was significantly associated with subsidence, but preoperative disc height was not associated with the subsidence (Table 7).
Table 6. Univariate analysis for the variables that affect pseudarthrosis and subsidence after one-level anterior cervical discectomy with stand-alone cage

\begin{tabular}{lllllll}
\hline \hline \multirow{2}{*}{ Variables } & \multicolumn{2}{c}{ Pseudarthrosis } & & \multicolumn{2}{c}{ Subsidence } \\
\cline { 2 - 3 } \cline { 6 - 7 } & $\begin{array}{c}\text { Odds } \\
\text { ratio }\end{array}$ & p-value & & $\begin{array}{c}\text { Odds } \\
\text { ratio }\end{array}$ & p-value \\
\hline Age $>60$ years & 0.679 & 0.561 & & 3.000 & 0.065 \\
Female gender & 0.524 & 0.302 & & 0.500 & 0.241 \\
Smoking history & 3.462 & 0.046 & & 2.917 & 0.068 \\
Implanted level (C5-C6) & 1.308 & 0.670 & & 0.943 & 0.920 \\
Cage style (PEEK cage) & 2.177 & 0.238 & & 0.676 & 0.510 \\
Cage height $\geq 7$ mm & 3.852 & 0.101 & & 12.565 & 0.019 \\
Allograft & 0.694 & 0.562 & & 1.048 & 0.936 \\
Angle of FSU (lordosis) & 3.852 & 0.101 & & 1.885 & 0.335 \\
Cervical curvature (lordosis) & 4.250 & 0.078 & & 1.400 & 0.589 \\
Preoperative disc height & 0.896 & 0.713 & & 1.924 & 0.039 \\
\hline
\end{tabular}

$\mathrm{Cl}$, confidence interval; PEEK, polyetheretherketone; FSU, functional segmental unit

Table 7. Multivariate analysis for the variables that affect pseudarthrosis and subsidence after one-level anterior cervical discectomy with stand-alone cage

\begin{tabular}{|c|c|c|c|c|}
\hline \multirow[b]{2}{*}{ Variables } & \multicolumn{2}{|c|}{ Pseudarthrosis } & \multicolumn{2}{|c|}{ Subsidence } \\
\hline & $\begin{array}{l}\text { Odds } \\
\text { ratio }\end{array}$ & p-value & $\begin{array}{l}\text { Odds } \\
\text { ratio }\end{array}$ & $\mathrm{p}$-value \\
\hline Age $>60$ years & 1.067 & 0.935 & 0.199 & 0.060 \\
\hline Female gender & 0.784 & 0.832 & 0.198 & 0.173 \\
\hline Smoking history & 0.173 & 0.023 & 0.201 & 0.122 \\
\hline Implanted level (C5-C6) & 0.471 & 0.348 & 0.766 & 0.744 \\
\hline Cage style (PEEK cage) & 1.042 & 0.968 & 0.153 & 0.083 \\
\hline Cage height $\geq 7 \mathrm{~mm}$ & 0.214 & 0.225 & 15.808 & 0.037 \\
\hline Allograft & 0.730 & 0.688 & 0.973 & 0.970 \\
\hline Angle of FSU (lordosis) & 6.097 & 0.095 & 1.321 & 0.754 \\
\hline Cervical curvature (lordosis) & 6.792 & 0.061 & 2.900 & 0.275 \\
\hline Preoperative disc height & 1.557 & 0.393 & 0.562 & 0.222 \\
\hline
\end{tabular}

$\mathrm{Cl}$, confidence interval; PEEK, polyetheretherketone; FSU, functional segmental unit

\section{Complications}

Postoperative complications occurred in $5(2.4 \%)$ of the 58 patients. In one patient, a hematoma developed in the cervical region, and an emergent hematoma evacuation was performed. In one patient, an iliac crest hematoma developed, which resolved on its own within 3 weeks of surgery. Three patients presented with postoperative hoarseness.

During the follow-up period, two patients presented with adjacent segment disease superior to the fused level, which was treated with further surgery. 


\section{DISCUSSION}

In the present study, arm pain, based on the preoperative and postoperative VAS, showed significant improvement. There was significant relief of neck pain and recovery of neck function after ACDF. Smoking history was significantly associated with the fusion status, and implanted cage height $\geq 7 \mathrm{~mm}$ was significantly associated with the development of subsidence. There were no differences in the clinical and radiological outcomes between the CFCFC and the PEEK cage groups.

Cages were introduced as a substitute for autologous iliac bone grafts and have been widely used because they avoid autograft harvesting-related complications. In the literature, although the fusion rate in patients who were treated with autografts is superior or similar to that of patients who were treated with cages, the clinical results were comparable bet-

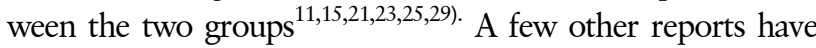
compared different cage systems ${ }^{6,16,19)}$. Matge et al. treated 228 cervical radiculopathy patients using five different cages that were composed of titanium or PEEK ${ }^{16}$ and reported that good to excellent results were achieved in most patients. Niu et al. reported on the outcomes of titanium and PEEK cages in 1- and 2-level ACDF procedures ${ }^{19)}$. Although the PEEK cages were superior to the titanium cages in maintaining the cervical interspace height and radiographic fusion, the two cage groups showed similar clinical outcomes. Chou et al. noted that the fusion rate was similar between the titanium and PEEK cages, but the complication rate was higher with the titanium cages compared to the PEEK cages ${ }^{6}$.

CFCFC and PEEK cages have some advantages over the titanium or metal cages. The elastic modulus of the CFCFC and PEEK cages are close to that of bone ${ }^{9)}$, which helps to decrease the stress shielding and to promote bony fusion as described in Wolff's law ${ }^{27)}$. The two cages investigated in the current study were radiolucent, which helps in the visualization of bone growth and repair with computed tomography and X-ray imaging. Furthermore, diagnostic MRI is possible for patients who underwent implantation with these cages because they are non-metallic. In the present study, despite the similar clinical outcomes, the radiological results were different between the CFCFC and the PEEK cage groups. The fusion rate was $68.6 \%$ (24 of 35 patients) in the CFCFC group and $82.6 \%$ (19 of 23 patients) in the PEEK cage group ( $\mathrm{p}=0.232$ ). In addition, the subsidence rate was $34.3 \%$ (12 of 35 patients) and $26.1 \%$ (6 of 23 patients) in the CFCFC and PEEK cage groups, respectively $(\mathrm{p}=0.509)$. These differences might be due to the differences between the elastic modulus of the CFCFCs and the PEEK cages. The elastic modulus of the CFCFCs
(45 GPa) is higher than that of the PEEK cages (3.4 GPa) ${ }^{9}$. Consequently, the stress shielding effect of the CFCFCs is higher than that of the PEEK cages, which might have resulted in the findings of the present study. However, based on the differences in the elastic modulus between the CFCFCs, the PEEK cages and the titanium cages, these radiological results of the present study are discouraging compared to those of patients implanted with titanium cages. Fusion rates between 70 and $100 \%$ were reported in patients who were implanted with titanium cages ${ }^{17,18,25,28)}$. Based on these findings, the radiological outcomes do not seem to be solely affected by the cage material. Furthermore, multivariate analyses revealed that cage style was not correlated with the radiological outcomes in the present study.

The role of smoking on the development of pseudarthrosis has been well documented in fusion ${ }^{1,3,12}$. Based on a rabbit lumbar fusion model, Daftari et al. proposed that the inhibition of revascularization of cancellous bone grafts by nicotine may be the mechanism by which smoking adversely affects fusions ${ }^{7}$. In the present study, the pseudarthrosis rate in the patients with a positive smoking history was more than 5 times that of the rate in the patients without a positive smoking history $(\mathrm{OR}=5.764 ; \mathrm{p}=0.023)$. Despite the negative effect of smoking on fusion, the clinical outcomes were not different between the smokers and nonsmokers in the present study. Hilibrand et al. reported that the nonsmokers had better functional status than the smokers in the group that underwent multilevel interbody grafting ${ }^{12}$. However, in the same study, the group that was treated with subtotal corpectomy and strut-grafting showed no significant differences between the clinical outcomes of the nonsmokers compared to the smokers. Although there was no conclusive evidence about the negative effect of smoking on the clinical outcomes, surgeons should be cautious about performing ACDF in patients who smoke. In addition, surgeons should inform the smokers who are scheduled for fusion surgery about the effects of smoking.

Subsidence in ACDF with the implantation of stand-alone cages has been problematic despite the theoretical advantages of cages. In the present study, cage height $\geq 7 \mathrm{~mm}$ was independent risk factors for subsidence based on the multivariate analysis. The selection of proper cage size is usually based on the measure of disc height obtained from preoperative radiographic images and by intraoperative evaluation using a trial cage to confirm initial stability. In the present study, subsidence occurred in 17 of 40 patients with an implanted cage height that was $\geq 7 \mathrm{~mm}$ but only in 1 of 18 patients with implanted cage height that was $<7 \mathrm{~mm}$, which represents a significant difference. In an in vitro study, it was shown that significantly higher distractive and compressive forces were correlated with larger grafts ${ }^{26}$. In an in vivo study, it was demonstrated that 
there was a statistically significant linear correlation between the distractive force that is applied across the discectomy site and the subsequent compressive force across a load cell in the interbody space following the distractor removal ${ }^{8)}$. These findings suggested that larger cage heights might require larger distractive forces to implant and consequently to produce a larger compressive force toward the end plate, which may cause subsidence of the cages after ACDF with stand-alone cages. In the current study, pseudarthrosis or subsidence did not affect the clinical outcomes, however, it never means that fusion is not necessary for clinical outcomes. Surgeons should be cautious about smoking history, and the selection of cage height in ACDF with stand-alone cages to prevent pseudarthrosis and subsidence.

Although further studies are required to determine the relationship between cage size and subsidence, surgeons should be cautious about the appropriate selection of cage sizes. The present study has several limitations. The retrospective nature of the review and the small patient population may limit the significance of the results. Because only $35.2 \%$ of the total 165 patients who underwent one-level ACDF procedures were investigated in the present study, the clinical and radiological outcomes could be influenced by selection bias. Because there was a statistically significant difference in some of the factors between the CFCFC and the PEEK cage groups, conclusions based on the comparison between the two groups may be limited. Another weakness of this study is regarding fusion criteria. We defined pseudarthrosis as a distance change of more than $2 \mathrm{~mm}$ between the tips of the spinous processes on flexion-extension lateral radiographs. However, this criterion has a limitation. Although the distance change of interspinous process is less than $2 \mathrm{~mm}$, there is a possibility of non-union. This is a reason that further study is needed with computerized tomography. And. although the mean follow-up period was more than 2 years, there was some patients with a follow-up period of less than 2 years. This follow-up period may not reflect the long-term outcome, and consequently, it is difficult to decisively conclude which cage system is more efficient in one-level ACDF with implantation of stand-alone cages.

\section{CONCLUSION}

The clinical and radiological results were similar in the patients who underwent ACDF with implantation of stand-alone CFCFCs compared to those who underwent implantation with PEEK cages. Although pseudarthrosis or subsidence did not affect the clinical outcomes, surgeons should be cautious about smoking history, and the selection of cage height in ACDF with stand-alone cages to prevent pseudarthrosis and subsidence.

\section{ACKNOWLEDGEMENT}

Nothing of value received from a commercial entity is related to this research

\section{REFERENCES}

1. An HS, Simpson JM, Glover JM, Stephany J: Comparison between allograft plus demineralized bone matrix versus autograft in anterior cervical fusion. A prospective multicenter study. Spine (Phila Pa 1976) 20:2211-2216, 1995

2. Bartels RH, Donk RD, Feuth T: Subsidence of stand-alone cervical carbon fiber cages. Neurosurgery 58:502-508; discussion 502-508, 2006

3. Bishop RC, Moore KA, Hadley MN: Anterior cervical interbody fusion using autogeneic and allogeneic bone graft substrate: a prospective comparative analysis. J Neurosurg 85:206-210, 1996

4. Cannada LK, Scherping SC, Yoo JU, Jones PK, Emery SE: Pseudoarthrosis of the cervical spine: a comparison of radiographic diagnostic measures. Spine (Phila Pa 1976) 28:46-51, 2003

5. Chau AM, Mobbs RJ: Bone graft substitutes in anterior cervical discectomy and fusion. Eur Spine J 18:449-464, 2009

6. Chou YC, Chen DC, Hsieh WA, Chen WF, Yen PS, Harnod $\mathrm{T}$, et al: Efficacy of anterior cervical fusion: comparison of titanium cages, polyetheretherketone (PEEK) cages and autogenous bone grafts. J Clin Neurosci 15:1240-1245, 2008

7. Daftari TK, Whitesides TE, Jr., Heller JG, Goodrich AC, McCarey BE, Hutton WC: Nicotine on the revascularization of bone graft. An experimental study in rabbits. Spine (Phila Pa 1976) 19:904-911, 1994

8. Francke EI, Demetropoulos CK, Agabegi SS, Truumees E, Herkowitz HN: Distractive force relative to initial graft compression in an in vivo anterior cervical discectomy and fusion model. Spine (Phila Pa 1976) 35:526-530, 2010

9. Galbusera F, Bellini CM, Anasetti F, Ciavarro C, Lovi A, BraydaBruno M: Rigid and flexible spinal stabilization devices: a biomechanical comparison. Med Eng Phys 33:490-496, 2011

10. Gercek E, Arlet V, Delisle J, Marchesi D: Subsidence of standalone cervical cages in anterior interbody fusion: warning. Eur Spine J 12:513-516, 2003

11. Hacker RJ, Cauthen JC, Gilbert TJ, Griffith SL: A prospective randomized multicenter clinical evaluation of an anterior cervical fusion cage. Spine (Phila Pa 1976) 25:2646-2654; discussion 2655, 2000

12. Hilibrand AS, Fye MA, Emery SE, Palumbo MA, Bohlman HH: Impact of smoking on the outcome of anterior cervical arthrodesis with interbody or strut-grafting. J Bone Joint Surg Am 83-a: 668-673, 2001

13. Jacobs WC, Anderson PG, Limbeek J, Willems PC, Pavlov P: Single or double-level anterior interbody fusion techniques for cervical degenerative disc disease. Cochrane Database Syst Rev: Cd004958, 2004

14. Lee CH, Hyun SJ, Kim MJ, Yeom JS, Kim WH, Kim KJ, et 
al: Comparative analysis of 3 different construct systems for single-level anterior cervical discectomy and fusion: stand-alone cage, iliac graft plus plate augmentation, and cage plus plating. J Spinal Disord Tech 26:112-118, 2013

15. Lofgren H, Engquist M, Hoffmann P, Sigstedt B, Vavruch L: Clinical and radiological evaluation of Trabecular Metal and the Smith-Robinson technique in anterior cervical fusion for degenerative disease: a prospective, randomized, controlled study with 2-year follow-up. Eur Spine J 19:464-473, 2010

16. Matge G: Cervical cage fusion with 5 different implants: 250 cases. Acta Neurochir (Wien) 144:539-549; discussion 550, 2002

17. Matge G, Leclercq TA: Rationale for interbody fusion with threaded titanium cages at cervical and lumbar levels. Results on 357 cases. Acta Neurochir (Wien) 142:425-433; discussion 434, 2000

18. Moreland DB, Asch HL, Clabeaux DE, Castiglia GJ, Czajka GA, Lewis PJ, et al: Anterior cervical discectomy and fusion with implantable titanium cage: initial impressions, patient outcomes and comparison to fusion with allograft. Spine J 4:184191; discussion 191, 2004

19. Niu CC, Liao JC, Chen WJ, Chen LH: Outcomes of interbody fusion cages used in 1 and 2-levels anterior cervical discectomy and fusion: titanium cages versus polyetheretherketone (PEEK) cages. J Spinal Disord Tech 23:310-316, 2010

20. Odom GL, Finney W, Woodhall B: Cervical disk lesions. J Am Med Assoc 166:23-28, 1958

21. Peolsson A, Vavruch L, Hedlund R: Long-term randomised comparison between a carbon fibre cage and the Cloward procedure in the cervical spine. Eur Spine J 16:173-178, 2007

22. Shrout PE, Fleiss JL: Intraclass correlations: uses in assessing rater reliability. Psychol Bull 86:420-428, 1979

23. Siddiqui AA, Jackowski A: Cage versus tricortical graft for cervical interbody fusion. A prospective randomised study. J Bone Joint Surg Br 85:1019-1025, 2003

24. Silber JS, Anderson DG, Daffner SD, Brislin BT, Leland JM, Hilibrand AS, et al: Donor site morbidity after anterior iliac crest bone harvest for single-level anterior cervical discectomy and fusion. Spine (Phila Pa 1976) 28:134-139, 2003

25. Thome C, Leheta O, Krauss JK, Zevgaridis D: A prospective randomized comparison of rectangular titanium cage fusion and iliac crest autograft fusion in patients undergoing anterior cervical discectomy. J Neurosurg Spine 4:1-9, 2006

26. Truumees E, Demetropoulos CK, Yang KH, Herkowitz HN: Effects of disc height and distractive forces on graft compression in an anterior cervical discectomy model. Spine (Phila Pa 1976) 27:2441-2445, 2002

27. Uhthoff HK, Dubuc FL: Bone structure changes in the dog under rigid internal fixation. Clin Orthop Relat Res 81:165-170, 1971

28. van Jonbergen HP, Spruit M, Anderson PG, Pavlov PW: Anterior cervical interbody fusion with a titanium box cage: early radiological assessment of fusion and subsidence. Spine J 5:645-649; discussion 649, 2005

29. Vavruch L, Hedlund R, Javid D, Leszniewski W, Shalabi A: A prospective randomized comparison between the cloward procedure and a carbon fiber cage in the cervical spine: a clinical and radiologic study. Spine (Phila Pa 1976) 27:1694-1701, 2002

30. Wigfield CC, Nelson RJ: Nonautologous interbody fusion materials in cervical spine surgery: how strong is the evidence to justify their use? Spine (Phila Pa 1976) 26:687-694, 2001 